\title{
Comparison of Methods of Expressing the Results of Augmented Histamine Tests
}

\author{
R. J. ABERNETHY,* F.R.C.S.ED. ; R. M. ROSS, ${ }^{*}$ F.R.C.S.lsD. ; A. G. COX, ${ }^{*} \dagger$ M.D., F.R.C.S.ED. \\ A. W. KAY, M.D., CH.M., F.R.C.s. ; I. E. GILLESPIE,* M.D., F.R.C.S.
}

Brit. med. F., 1967, 3, 205-206

The augmented histamine test (Kay, 1953) has been widely used as a reliable means of measuring maximal acid secretion by the stomach. There is general agreement that the dose of histamine $(0.04 \mathrm{mg} . / \mathrm{kg}$. body weight) recommended by Kay evokes a maximal or near-maximal acid response. However, the period during which the response is greatest is the subject of dispute, and workers have used the acid output in different periods to report their results. Most have used the response in the 30-minute period from 15 to 45 minutes after the histamine injection, as originally suggested by Kay. Baron (1963) showed that the maximal response did not always coincide with this period and suggested that the greatest halfhour response (the " peak half-hour") should be used whenever it occurred. Other workers have referred to the secretion during the whole 60-minute period after histamine as the maximal histamine response (Bruce et al., 1959).

If the results of augmented histamine tests are expressed in different ways the conclusions may also differ. In this paper we present a detailed analysis of the effect of reporting the results in these different ways. The data are taken from acid tests in a consecutive series of 100 patients with duodenal ulcer studied before and after vagotomy with a simple drainage procedure.

\section{Materials and Methods}

Each patient had an augmented histamine test and a "medical vagotomy" test (Gillespie and Kay, 1961) before operation, and an augmented histamine test and an insulin test approximately 8 to 10 days after operation. Each test was carried out after a 12-hour fast. Before operation a radioopaque nasogastric tube was passed under fluoroscopic control. In the postoperative tests use was made of a gastrostomy tube placed in the stomach at operation. Gastric secretions were collected by continuous suction by electric pump, with occasional interruption to ensure patency.

In the augmented histamine test four basal specimens were aspirated at 15-minute intervals after removal of the fasting juice. Mepyramine maleate, $50 \mathrm{mg}$., was injected intramuscularly, and 30 minutes later histamine acid phosphate, 0.04 mg. $/ \mathrm{kg}$. of body weight, was given by subcutaneous injection. Thereafter 15-minute aspirates were collected for one hour.

In the medical vagotomy test a combination of hexamethonium bromide, $50 \mathrm{mg}$., and atropine sulphate, $0.325 \mathrm{mg}$., was given as a single deep intramuscular injection one and a half hours before the injection of histamine. The details of antihistamine and histamine dosage and timing were otherwise the same as in the augmented histamine test.

In the insulin test 20 units of soluble insulin was given intravenously after collection of two 15-minute basal specimens. Blood sugar concentration fell to below $35 \mathrm{mg} . / 100 \mathrm{ml}$. in all cases. Fifteen-minute aspirates were collected for two hours after the insulin injection.

The volume of each 15-minute specimen was measured. After filtration acid concentration was measured by titration

\footnotetext{
- University Department of Surgery, Western Infirmary, Glasgow W.1. t Present address: Department of Surgery, Royal Postgraduate Medical School, London W.12.
}

against 0.1 normal sodium hydroxide with phenol red as indicator (end-point $p H$ 6.8-8.4). Acid outputs were obtained by multiplication of volume and concentration values and expressed as $\mathrm{mEq}$.

The response to the insulin test was classified as positive if the criteria of Hollander (1951) were satisfied at any time within the two hours of collection of specimens after the insulin injection. A positive response was denoted by an increase in acid concentration of more than $20 \mathrm{mEq} / \mathrm{l}$. over basal concentration or by an increase in concentration of more than $10 \mathrm{mEq} / 1$. in the presence of basal anacidity.

\section{Analysis of Results}

For the purposes of this analysis the results of all augmented histamine tests were expressed in three different ways: (1) "mid-half-hour," acid output in the 15- to 45-minute period after histamine ; (2) "peak half-hour," acid output in the 30-minute period giving the greatest response after histamine ; and (3) "whole hour," acid output in the 60 minutes after histamine. Each of these methods of reporting the results was compared with each of the others by calculating the correlation coefficient between each possible pair.

Table I shows the exceptionally high degree of correlation between each pair of measurements in $(a)$ the preoperative augmented histamine response, $(b)$ the medical vagotomy modification, and $(c)$ the postoperative augmented histamine response. Similarly, as shown in Table II, there was good correlation between the three pairs of measurements when the effects of medical and surgical vagotomy were expressed as percentage reductions of the preoperative augmented histamine response. These correlations were not so close to unity, because each point represents the results of four tests. Despite this, all correlation coefficients were statistically significant.

Within the series of 100 patients there were subgroups which differed significantly one from the other with regard to

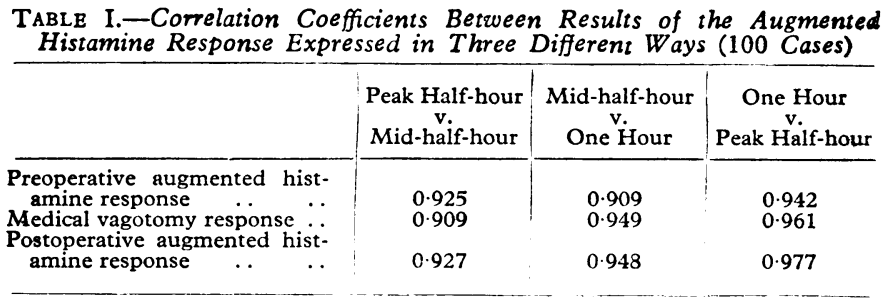

All correlation coefficients are statistically significant $(\overline{P<0.001})$.

TABLE II.-Correlation Coefficients Between Reduction of Augmented Histamine Response by Medical and Surgical Vagotomy Expressing the Results in Three Ways

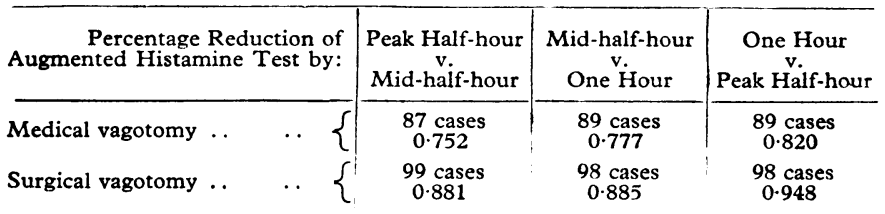

All correlation coefficients are statistically significant $(P<0.001)$. 
augmented histamine response. A notable example was the difference between the two sexes, the males secreting more acid than the females. It was of interest to see whether this difference was quantitatively the same with each of the different methods of expressing the augmented histamine response. Table III shows that the male/female ratios for all three methods were virtually identical, as were the Student's $t$ test values for each.

TABLE III.-Comparison of Differences Between Male and Female Preoperative Augmented Histamine Responses with the Three Methods of Expression (Standard Deviations in Parentheses)

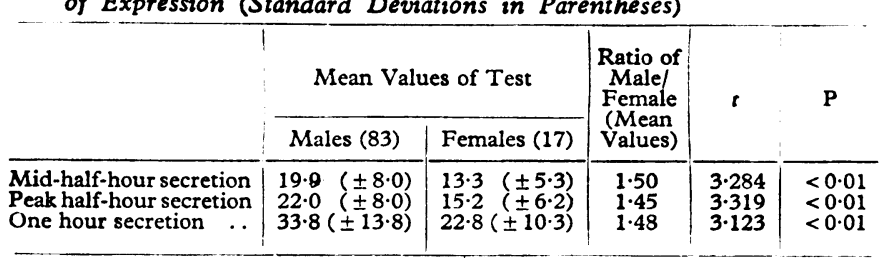

Finally, the effect of taking the three different estimates of augmented histamine response was observed in comparing two subgroups whose responses differed by a much smaller amount. These were the group with a negative response to insulin and the group with a small positive response occurring late in the two-hour collection period after the insulin injection. Though the classification of this late type of insulin response was made on an arbitrary basis, it had previously been found that the reduction in augmented histamine response due to vagotomy in patients comprising this subgroup was greater than the reduction in those with large and early positive insulin responses, and only slightly less than the reduction seen in those with completely negative insulin responses (Ross and Kay, 1964). Table IV shows that the relation between the two insulin groups is virtually the same regardless of the method used to express the augmented histamine responses.
TABLE IV.-Comparison of Percentage Reduction in Augmented Histamine Response in Patients with a Negative Insulin Test, and Those with a "Late Pcsitive" Insulin Test After Vagotomy and Drainage (Standard Deviations in Parentheses)

\begin{tabular}{|c|c|c|c|c|c|}
\hline & \multicolumn{2}{|c|}{$\begin{array}{c}\text { Percentage Reduction of Aug- } \\
\text { mented Histamine Response }\end{array}$} & \multirow{2}{*}{$\begin{array}{c}\text { Ratio of } \\
\% \text { Reduc- } \\
\text { tions: } \\
\text { Negative/ } \\
\text { Positive }\end{array}$} & \multirow{2}{*}{$t$} & \multirow{2}{*}{$\mathbf{P}$} \\
\hline & $\begin{array}{l}\text { Insulin } \\
\text { Negative } \\
\text { (69 cases) }\end{array}$ & $\begin{array}{l}\text { Insulin " Late } \\
\text { Positive" } \\
\text { (27 cases) }\end{array}$ & & & \\
\hline $\begin{array}{l}\text { Mid-half-hour out- } \\
\text { put } \\
\text { Peak half-hour out- }\end{array}$ & $75 \%( \pm 18 \cdot 3)$ & $56 \%( \pm 19 \cdot 3)$ & 1.34 & $4 \cdot 551$ & $<0.01$ \\
\hline $\begin{array}{l}\text { put } \\
\text { One hour output.. }\end{array}$ & $\begin{array}{l}69 \%( \pm 17.5) \\
73 \%( \pm 18.9)\end{array}$ & $\begin{array}{l}54 \%( \pm 20 \cdot 8) \\
58 \%( \pm 20 \cdot 4)\end{array}$ & $\begin{array}{l}1 \cdot 28 \\
1 \cdot 26\end{array}$ & $\begin{array}{l}3.579 \\
3.377\end{array}$ & $\begin{array}{l}<0.01 \\
<0.01\end{array}$ \\
\hline
\end{tabular}

\section{Conclusions and Summary}

It can be seen from Tables I and II that there was a highly significant degree of correlation between the three methods of expressing the results. Tables III and IV show that when differences exist between the results of subgroups of patients within the series these differences are of the same magnitude, regardless of the way in which the results are expressed.

We therefore conclude that variations in the method of expressing the results of the augmented histamine test are unlikely to alter the conclusions derived from a particular series of such tests. It is likely, therefore, that conclusions in studies using different ways of expressing the test responses can be directly related one with another.

\section{REFERENCES}

Baron, J. H. (1963). Gut, 4, 136.

Bruce, J., Card, W. I., Marks, I. N., and Sircus, W. (1959). F. roy. Coll. Surg. Edinb., 4, 85.

Gillespie, I. E., and Kay, A. W. (1961). Brit. med. F., 1, 1557.

Hollander, F. (1951). Meth. med. Res., 4, 166.

Kay, A. W. (1953). Brit. med. Y., 2, 77.

Ross, B., and Kay, A. W. (1964). Gastroenterology, 46, 379.

\title{
Late Changes in Peripheral Blood after Thorotrast Administration
}

\author{
A. O. LANGLANDS,* M.B., CH.B., B.SC., D.M.R.T., F.F.R.; E. R. D. WILLIAMSON,* M.B., B.CH.
}

Brit. med. F., 1967, 3, 206-208

From its introduction in 1930 a stabilized colloidal suspension of ${ }^{232}$ thorium dioxide (Thorotrast) was extensively used either to outline body cavities, such as the renal pelvis or the paranasal sinuses after direct injection, or as a contrast medium in angiography, and, after deposition, for visualization of the liver and spleen. Its use was largely discontinued in 1947 after the report of MacMahon et al. (1947) on the first malignancy due to Thorotrast. Horta et al. (1965) reported a follow-up study of some 1,100 persons who had received Thorotrast. In addition to malignancies arising at sites of Thorotrast deposition 16 deaths out of a total of 699 were due to leukaemia, aplastic anaemia, or purpura.

We have recently undertaken a study of patients who had received intra-arterial Thorotrast, in an attempt to obtain information on the morbidity and haematological and cytogenetic changes due to Thorotrast. The purpose of this communication is to report the findings on examination of peripheral blood from these patients.

* M.R.C. Clinical Effects of Radiation Research Unit, Western General Hospital, Edinburgh 4.

\section{Material and Methods}

Between 1930 and 1947, during investigation in the department of surgical neurology, Edinburgh, 137 patients received intra-arterial Thorotrast. In 1966 there were 37 survivors still residing in Edinburgh or near by. A venous blood sample was obtained from 35, comprising 18 men and 17 women. With one exception all had received Thorotrast before 1947.

The details of Thorotrast administration in these patients are summarized in Table $\mathrm{I}$.

Packed cell volumes were determined according to the method described by Dacie and Lewis (1963); haemoglobin was esti-

TABLB I

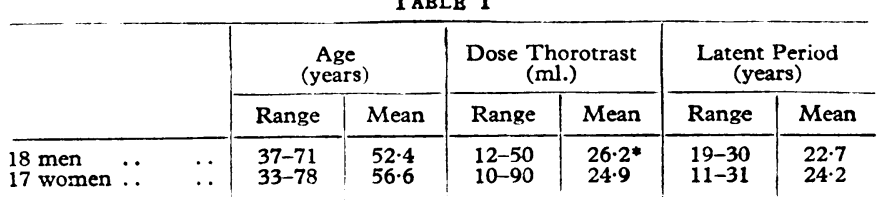

* Based on 13 cases. The dose was unrecorded in five. 